\title{
A DIALÉTICA ENTRE SISTEMA E PROBLEMA: COORDENADAS METODOLOGICAMENTE COMPLEMENTARES E IRREDUTÍVEIS DO JUDICIUM JURÍDICO
}

THE DIALECTIC BETWEEN SYSTEM AND PROBLEM: COORDINATES METHODOLOGICALLY COMPLEMENTARY AND IRREDUCIBLE OF DECISION-MAKING PROCESS OF THE COURTS

\author{
Lúcio Grassi de Gouveia \\ Mateus Costa Pereira
}

\section{Resumo}

0 presente artigo pretende, diante da contribuição da retórica para a filosofia do direito, demonstrar a viabilidade da compatibilização entre os pensamentos sistemático e problemático, que não devem ser enxergados como opostos exclusivistas, mas como coordenadas metodologicamente complementares e irredutíveis do processo decisório dos tribunais.

Palavras-chave: Teoria metodológica do direito. Dialética. Sistema e problema.

\begin{abstract}
This paper intends, on the rhetorical contribution to the philosophy of law, demonstrate the feasibility of reconciling the systematic thinking and problem that should not be seen as exclusivist opposites, but as methodologically complementary coordinates and irreducible the decision-making process of the courts.
\end{abstract}

Keywords: Methodological theory right. Dialectics. System and problem. 


\section{INTRODUÇÃo}

Durante a realização dos estudos do grupo de pesquisa Processo, Tecnologia e Hermenêutica do Programa de Pós-graduação em Direito da Universidade Católica de Pernambuco, temos nos deparado com trabalhos de doutrinadores das áreas de Teoria Geral do Direito, Hermenêutica Jurídica e Teoria Geral do Processo que supervalorizam, no processo de tomada de decisões por juízes e tribunais brasileiros, a busca da "verdade" e da única decisão correta. Para eles, havendo divergência entre dois julgamentos realizados por juízes ou tribunais diversos, somente um estaria correto e o outro seria considerado fruto de desvio técnico, na melhor das hipóteses, ou mesmo ético.

Em recente e brilhante palestra no mesmo programa o Professor Doutor Manuel Atienza, catedrático da Universidade de Alicante na Espanha, afirmou que aqueles que abdicam de encontrar solução para o problema da busca da decisão correta para casos concretos seriam, de fato, notórios conservadores. Em outras palavras, seriam conservadores todos aqueles que se afastam do pensamento ontológico e se aproximam, por um motivo ou outro, do pensamento retórico.

O conservadorismo ou conservantismo é um termo usado para descrever posições político-filosóficas, alinhadas com o tradicionalismo e a transformação gradual, que em geral se contrapõem a mudanças abruptas (cuja expressão máxima é o conceito de revolução) de determinado marco econômico e político-institucional ou no sistema de crenças, usos e costumes de uma sociedade.

Teriam os retóricos tais características ou teriam chegado à condição de céticos diante de problemas insuperáveis que nunca foram enfrentados adequadamente pelos ontológicos? Entendemos que a questão não é tão simples, como faz supor Atienza.

Por outro lado, tal questionamento leva-nos a enfrentar questões metodológicas decisivas e fundamentais para a adequada compreensão do tema.

Ao tratarmos de uma teoria metodológica para o Direito, temos que ter em mente que não se trata de um movimento científico homogêneo. Temos nos deparado, no cenário jurídico-filosófico, com várias correntes de pensamento, das quais destacaremos três: aqueles que ainda acre- 
ditam em um modelo clássico de aplicação e subsunção para o direito, tradicionalmente atribuído ao positivismo jurídico-científico; outros que continuam enfatizando a busca da verdade, mas defendem um modelo de concretização, formulado com base na hermenêutica jurídica do século XX, já que uma argumentação jurídica teria que ir além de métodos dedutivos lógicos, em virtude do caráter indeterminado das "premissas maiores" e tendo em mente que a própria interpretação judicial é produtiva ou criativa; e ainda aqueles que possuem uma visão cética, que sequer acreditam na busca da verdade (retóricos), como fazem os dois primeiros (ontológicos), tendo em vista que consideram pouco provável que uma previsão normativa genérica e idealizada controle uma futura decisão única e correta, já que a linguagem não seria um meio para o mundo real, mas o único mundo perceptível - o conhecimento formado por acordos linguísticos de maior ou menor permanência no tempo, mas todos circunstanciais, temporários, autorreferentes e passíveis de constantes rompimentos (ADEODATO, 2011, p. 7).

0 ponto central da discussão está na verdade no profundo e eterno debate entre ontológicos e retóricos. Nada mais ilustrativo desse debate que o conhecido confronto entre Parmênides e Heráclito: para aquele tudo permanece e nada muda; para este, tudo muda e nada permanece.

Na base uma questão gnoseológica. Como bem disse João Maurício Adeodato, na passagem da atividade cerebral (ideia) para a articulação (discurso) parece estar o ponto crucial da teoria do conhecimento. A questão central de toda a gnoseologia é investigar esse processo de exteriorização, este relacionamento entre percepções de dados que nos parecem ocorrer no nosso próprio corpo (mente, cérebro) e percepções de dados que nos parecem ocorrer fora dele (mundo). Diante desta questão podemos dividir os diversos argumentos que tentam solucioná-lo em dois grandes grupos, ressalvadas a dose de arbitrariedade e as limitações propriamente epistemológicas de todo o modelo didático: por um lado, os que partem do postulado de que a linguagem humana constitui um meio para expressar uma realidade objetiva (teorias ontológicas); por outro, os argumentos que se baseiam numa autonomia do discurso - a linguagem não teria outro fundamento além de si mesma - não havendo elementos externos à linguagem (fatos, objetos, coisas, relações) que 
possam legitimá-la (teorias retóricas). Surge a dicotomia entre privilegiar regras gerais para decidir conflitos que ainda estão para ocorrer ou privilegiar a decisão casuística, em concreto. Entre enfatizar as regras gerais como fazem jusnaturalistas, racionalistas, muitas escolas positivistas e sociologistas que acreditam na verdade (num homem como ser pleno capaz de atingir esse estágio) ou proclamar maior independência da decisão diante do caso concreto, como fazem os sofistas, os céticos, cínicos e nominalistas, que relativizam o conhecimento (visualizando o homem como ser carente e incapaz de atingir a verdade, que considera a língua como única realidade artificial que é capaz de lidar). Entre considerar que a linguagem humana descreve as coisas como são ou se sua relação com estas reduz-se a uma convenção que os homens estabelecem arbitrariamente. Entre essencialismo e nominalismo. Entre ser em si e ser para nós. Entre criticismo kantiano e ceticismo. Entre saber o que é em si e preocupar-se sobre como podemos falar sobre algo de forma clara e coerente (ADEODATO, 1996, p. 195-198).

O fenômeno jurídico-metodológico não poderia escapar dessa investigação. Presenciamos assim um eterno debate entre teorias ontológicas e retóricas na tentativa de explicação do delicado processo de realização do direito. Nesse sentido, de um lado o pensamento ontológico enraizado em Hegel com expoentes em Heidegger e Gadamer e de outro o pensamento problemático, enraizado em Viehweg e Perelman. Veremos que um adequado enfoque do pensamento jurídico moderno, no que diz respeito à metodologia jurídica, passa por uma tomada de posição diante dessa delicada questão.

Dessa maneira, há muito tempo se discute se o processo jurídico-decisório centra-se no sistema ou no problema. Entre as atuais correntes que procuram explicar o processo decisório percorrido pelos julgadores na atividade de realização do direito, discordam em seus pontos de vista defensores dos pensamentos sistemático e problemático.

Seriam opostos excludentes ou poderiam conviver de forma harmônica?

É justamente a essa pergunta que o presente artigo pretende responder. Justifica-se a presente pesquisa, na necessidade de efetuar um aprofundamento desse tema de grande complexidade, tendo em vista a neces- 
sidade cada vez maior de o Poder Judiciário brasileiro decidir questões de grande complexidade, muitas vezes envolvendo efetivação de direitos sociais relevantes, diante da omissão do Estado.

A cientificidade da pesquisa está diretamente relacionada à determinação dos métodos de estudo. Tendo em vista o caráter teórico da pesquisa, será utilizado material preponderantemente bibliográfico. Para propiciarmos o aprofundamento temático, empregaremos o método lógico dedutivo, tendo em vista a natureza doutrinária da pesquisa. Nos utilizaremos assim de ampla pesquisa bibliográfica em monografias, teses e artigos científicos, de forma a coletarmos as informações mais relevantes acerca do tema suscitado.

Quanto à estrutura do artigo, no decorrer do trabalho aprofundaremos a ideia de linguagem como único mundo perceptível para o intérprete/aplicador do direito. Afastaremos o esquema clássico lógico-dedutivo de aplicação do direito, que pouca ou nenhuma contribuição apresenta dos dias de hoje, quando o Judiciário, a todo o momento, é chamado a decidir, emitindo juízos de valor em questões de alta complexidade. Estabeleceremos a base do confronto entre ontológicos e retóricos, com suas tentativas extremadas para a solução do problema. E finalmente, apresentaremos posição que procure conciliar os opostos, dando grande ênfase à contribuição retórica, que nada tem de conservadora.

Comecemos, portanto, antes de responder à pergunta acima formulada, pela análise da questão do uso da linguagem pelo intérprete/aplicador do direito, um dos fatores relevantes para que entendamos a ênfase crescente que tem sido dada ao pensamento problemático no direito.

\section{A LINGUAGEM NÃO É MEIO PARA O MUNDO REAL, MAS O ÚNICO MUNDO PERCEPTÍVEL}

A retórica parte da ideia de uma antropologia carente, da linguagem não como meio para o mundo real, mas o único mundo perceptível.

Desde Platão, a Filosofia baseava-se na ideia de que o ato de conhecer constituía-se da relação entre sujeito e objeto e que a linguagem servia como instrumento, cuja função era expressar a ordem objetiva das coisas. Acreditava-se que por meio da linguagem o sujeito se conectava 
ao objeto, porque esta expressava sua essência (correspondência entre ideias e coisas que eram descritas pela linguagem, de modo que o sujeito mantinha uma relação com o mundo anterior a qualquer formação linguística). 0 conhecimento era concebido como reprodução intelectual do real, sendo a verdade resultado da correspondência entre tal reprodução e o objeto referido. Uma preposição era considerada verdadeira quando demonstrava a essência de algo, já que a linguagem não passava de um reflexo, uma cópia do mundo (CARVALHO, 2013, p. 14).

0 estudo do conhecimento, durante o decurso dos séculos, foi feito a partir do sujeito (gnoseologia), do objeto (ontologia), ou da relação entre ambos (fenomenologia) e a linguagem foi sempre considerada como instrumento secundário do conhecimento.

Segundo essa tradição filosófica, existia um mundo em si, refletido pela palavras (filosofia do ser) ou conhecido mediante atos de consciência e depois fixado e comunicado aos outros por meio da linguagem (filosofia da consciência). A linguagem não era condição do conhecimento, mas um instrumento de representação da realidade tal qual ela se apresentava e era conhecida pelo sujeito cognoscente.

Em meados do século passado, houve mudança na concepção filosófica do conhecimento, denominada de giro-linguístico, cujo termo inicial é marcado pela obra de Ludwig Wittgenstein. Foi quando a filosofia da consciência deu lugar à filosofia da linguagem. Segundo tal concepção, a linguagem deixa de ser apenas instrumento de comunicação de um conhecimento já realizado e passa a ser condição de possibilidade para constituição do próprio conhecimento enquanto tal. Este não é visto mais como uma relação entre sujeito e objeto, mas sim entre linguagens.

Não existe mais um mundo em si, independente da linguagem, que seja copiado por ela, nem uma essência nas coisas para ser descoberta. Só temos o mundo e as coisas na linguagem: nunca em si. Assim não há correspondência entre linguagem e objeto, pois este é criado por ela. A linguagem, nesta concepção, passa a ser o pressuposto por excelência do conhecimento.

O ser humano só conhece o mundo quando o constitui linguisticamente em seu intelecto. Por isso Maturana e Varela afirmam que "todo ato de conhecimento produz um mundo". Conhecer não significa mais 
simples apreensão mental de uma dada realidade, mas a sua construção intelectual, o que só é possível mediante linguagem. Segundo Heidegger nosso "ser-no-mundo" é sempre linguisticamente mediado. A linguagem é a morada do ser, o lugar onde o sentido do ser se mostra (CARVALHO, 2013, p. 15-19).

Não utilizamos a linguagem para manipular o real, mas antes, ela nos determina e nela se dá a criação daquilo que chamamos de realidade. Pela linguagem podemos conhecer os dados físicos, identificá-los e transformá-los numa realidade objetiva para nosso intelecto.

Assim, se tradicionalmente a verdade era tida como relação entre sentença e coisa, rejeita-se tal relação, já que não existe qualquer relação entre sentença e coisa, mas apenas entre sentença e outras sentenças.

A verdade não se descobre, pois não há essências a serem descobertas, ela se inventa, se constrói linguisticamente dentro de um sistema referencial, juntamente com a coisa. 0 que era verdade ontem pode não ser hoje.

Dessa forma, tais avanços no campo da linguística propiciaram uma relativização do conceito de verdade no direito e permitiram que os juristas se mostrassem mais abertos às contribuições da retórica.

\section{A FALÊNCIA DO ESQUEMA CLÁSSICO LÓGICO- DEDUTIVO DE APLICAÇÃO DO DIREITO}

Por incrível que pareça, é comum nos dias de hoje encontrarmos em certos manuais e livros acadêmicos menções a um modelo clássico de interpretação e aplicação do direito baseado em um método lógico dedutivo, onde a subsunção tem um papel de destaque. Nesse modelo enfatiza-se a busca da única resposta correta pelo intérprete/aplicador do direito. 0 que estivesse fora desse padrão deveria ser considerado desvio técnico ou ético, ignorância, incompetência ou falta de preparo deste.

O esquema clássico de realização do Direito assentava em dois pilares essenciais: a compartimentação do processo interpretativo-aplicativo e o método de subsunção. Tal processo era decomposto em várias operações: a determinação da fonte relevante, a sua interpretação, a integração de eventuais lacunas, a delimitação da matéria de fato resultante, a sua qualificação jurídica e a aplicação. Tal entendimento seria resultado de uma 
concepção jusracionalista de separação de poderes e do estilo savigniano da formação dos conceitos, na degenerescência subsequente conhecida por elaboração conceitual do Direito (CORDEIRO, 1989, p. CI).

Mantida a importância da noção de sistema em direito, mas de sistema aberto e móvel, observamos que atualmente prevalece o entendimento de que, na busca pelo aplicador do direito do sentido adequado da norma, o método lógico-dedutivo não pode ser utilizado em sua pureza, considerando a norma geral e abstrata (premissa maior), o fato concreto (premissa menor) e a norma individual e concreta (conclusão), ligadas somente por procedimentos lógicos e sem qualquer participação valorativa do aplicador do direito.

A questão se amplia nos dias de hoje, quando a hermenêutica jurídica já pacificou a distinção entre texto e norma e enfatizou a importância dos princípios na construção da decisão que irá reger o caso concreto.

E muitos são os obstáculos para a aplicação do método lógico-dedutivo: a ocorrência de normas vagas, indeterminadas, suscetíveis de concretização, apenas, no caso concreto; a incompletude do sistema; a ocorrência de contradições de princípios; a existência, por fim, de soluções injustas e inconvenientes (CORDEIRO, 1989, p. CIII).

Dessa forma, não é a refutação do pensamento sistemático que solucionará o problema da construção de uma teoria capaz de explicar o processo decisório pelos aplicadores do direito, sendo porém imprescindível que sejam afastadas aquelas teorias que procuram explicá-lo como procedimento lógico-dedutivo, no qual a uma premissa maior que é a norma jurídica se subsuma a premissa menor, que corresponde à situação fática, chegando-se silogisticamente a uma conclusão única e correta.

Verificada a inadequação da aplicação do método lógico-dedutivo em sua pureza, surgiram entendimentos mais brandos, como o defendido por Engish, de que, a partir da premissa maior, intercalam-se diversas premissas menores que possibilitam a subsunção do fato à norma, para assim possibilitar a fixação da norma individual e concreta, como conclusão. A norma geral e abstrata formar-se-ia pela observação das normas do sistema jurídico que interessassem ao caso concreto, aplicadas conjuntamente. As premissas menores, a partir de uma situação concreta onde as normas processuais garantiriam o enquadramento da conduta concreta 
ao tipo e a prova de que tal fato é imputável à determinação do sujeito. Assim, utilizando-se da lógica dedutiva, poder-se-ia formar a conclusão, a decisão do órgão aplicador do direito (ENGISH, 1988, p. 124-126).

Koch e Russmann chegam a afirmar que a subsunção, com o auxílio da interpretação, estaria viabilizada mesmo no caso em que a lei emprega conceitos vagos ou descrições de tipos. 0 posicionamento de Koch e Russmann pode ser visto como uma reação aos ataques sofridos pelo modelo lógico-dedutivo de aplicação do direito. Procuram comprometer tanto quanto possível o juiz em relação à indicação de fundamentos comprováveis de suas decisões, sem margem para apelo ao sentimento jurídico, à eqüidade ou idéias gerais vagas. Tal assertiva não resiste ao mais simples exame metodológico, já que conceitos vagos como as expressões "irrelevante", "preponderante", têm uma amplitude oscilante no seio da qual não se pode dizer com segurança se os diversos casos concretos que se lhe apresentam estariam ou não compreendidos em suas esferas (KOSH/RÜSSMANN apud LARENZ, 1989, p. 185). Para parte da doutrina, porém, poder-se-ia falar, por exemplo, em subsunção, quando o legislador se limitasse à utilização de grandezas quantitativas ou temporais fixas.

Prevalece o acertado entendimento atual de que o ponto específico da interpretação, o apreender do sentido ou do significado de um termo ou de uma proposição no contexto de uma cadeia de regulação, iria para além das regras lógicas, considerando sua razoabilidade e apreciações subjetivas do texto normativo. 0 processo de dedução da maior parte das decisões, a partir da lei, por meio de uma subsunção lógica, seria inadequado ou de pouco significado.

Como o processo de definição, e com ele o de derivação lógica por meio do silogismo de subsunção, não pode ser indefinidamente prosseguido, necessita-se, mais cedo ou mais tarde, de certos juízos elementares que, por seu lado, já não são proporcionados por silogismos, mas que assentam em percepções (próprias ou alheias) - juízos de percepção - ou em determinadas experiências, em especial as que pertencem ao âmbito das experiências sociais.

No universo das críticas ao modelo subsuntivo, destaca-se a de Larenz, para quem "a subsunção considerada como tal, oblitera a participação do julgador. A subordinação de uma situação de fato $S$ sobre a previsão 
P, por via de um silogismo de subsunção, só é possível se P puder ser plenamente definido mediante a indicação, que seja suficiente, de determinadas notas, ou, por outras palavras, quando com a caracterização de $\mathrm{P}$ mediante as notas $\mathrm{N} 1$ até $\mathrm{N}^{*}$ se trate da definição de um conceito, o que não é sempre o caso" (LARENZ, 1989, p. 328-329).

Partidário de uma coordenação valorativa e não subsunção, Larenz entende que na apreciação de uma situação de fato, para se descobrir se esta recai na previsão de uma das proposições jurídicas potencialmente aplicáveis, exige-se do julgador juízos baseados na interpretação da conduta humana, outros juízos proporcionados pela experiência social, juízos de valor e uma margem de livre apreciação por parte do juiz, quando na impossibilidade de utilização de ponderações convincentes (LARENZ, 1989, p. 340).

0 processo de uma dedução da maior parte das decisões, a partir da lei, por meio de uma subsunção lógica (de situação de fato sob a previsão de uma norma legal) ou é geralmente inadequado ou tem significado mínimo. 0 ponto central da construção da norma e da justificação da decisão, na maioria das vezes, reside em juízos de valor por parte do juiz.

Segundo Castanheira Neves, tudo levava a concluir que os metódicos esquemas lógicos não eram senão esquemas de exposição de uma atividade ou atos jurídicos cuja constituição tinha outra sede e se determinava de outro modo; e sobretudo que o esquema silogístico-subsuntivo não era mais do que o esquema lógico de justificação ex post de aplicações do direito constituídas ex ante por intenções de índole diversa - o que era afinal cobrir com a aparência de uma estrita e puramente dedutiva aplicação de pressupostas normas jurídicas, e bem assim do sistema dogmático que com elas se elaborava, uma realidade judicativa de todo diferente (NEVES, 1995, p. 259).

Métodos estritamente lógicos não têm aplicação na maioria dos casos, sejam naqueles conhecidos pela doutrina tradicional como de interpretação jurídica ou mesmo na denominada integração jurídica. Até por que em muitos casos o legislador, muitas vezes propositadamente, deixa uma certa margem de livre apreciação para o realizador do direito. Mas mesmo nesta livre margem de apreciação, alguns casos que se lhe apresentam são típicos e contêm semelhanças marcantes 
com casos já resolvidos. Existe ainda uma pequena minoria de casos em que a decisão depende única e exclusivamente da valoração do juiz que, neste caso, deve tomá-la.

Assim, a comparação e a ponderação valorativas devem atuar no lugar da subsunção. Se as regras da coerência lógica nos dão uma possibilidade de fundamentar a verdade jurídica, não são suficientes para caracterizar uma definição, uma interpretação, ou uma decisão como certa, verdadeira ou justa.

Admitir-se, porém, que o rigor lógico-dedutivo não é suficiente para resolver a ampla gama de questões que se apresentam ao julgador não é defender o irracionalismo pregado por alguns realistas, que elegeram o elemento volitivo do aplicador do direito como ponto fundamental do processo decisório. Não é admitir concepções como as propostas por Sobota, Brutau e Ballweg, segundo as quais o juiz primeiro chega ao resultado para depois procurar as normas e princípios que o justifiquem, ficando assim as decisões judiciais ao sabor dos estados de humor e dieta dos juízes, tendo a lei pouca ou nenhuma importância.

Porém, o ordenamento jurídico não tem condições de prever todas as hipóteses de casos concretos que ocorrem em nossa vida social e mesmo que se tivesse esta pretensão, a linguagem natural e aberta utilizada pelo legislador propicia ao intérprete-aplicador do direito grande margem de liberdade para a realização de uma interpretação objetivista-atualista, de natureza teleológica, atualizando a norma jurídica sem afrontá-la.

Considere-se ainda o fato de que o legislador muitas vezes utiliza-se de conceitos vagos e ambíguos para propiciar ao realizador do direito uma maior abertura na decisão de casos concretos, visto entender que em tais casos este tem melhores condições de valorar a situação fática na tomada de decisões. Engish divide-os em conceitos indeterminados, conceitos normativos, conceitos discricionários e as chamadas cláusulas gerais (ENGISH, 1988, p. 209) ${ }^{1}$. A existência de tais conceitos ao lado da estrutura aberta da linguagem e da existência de lacunas consistem em fatores que colaboram para ineficácia de um modelo lógico-dedutivo de aplicação do direito.

A linguagem utilizada nos comandos normativos não corresponde à utilizada em uma lógica axiomatizada ou na linguagem das ciências, que 
possuem um conteúdo e alcance rigorosamente fixados. A linguagem da lei é dotada de certa flexibilidade, em que o possível significado oscila em uma maior ou menor margem de tolerância. Afetam este significado as circunstâncias, a relação objetiva e o contexto do discurso, a colocação da frase e a entoação de uma palavra. Conceitos em certa medida fixos possuem notas distintivas que carecem de uma delimitação rigorosa (LARENZ, 1989, p. 376) ${ }^{2}$.

Quanto à relação entre interpretação e linguagem, Castanheira Neves afirma que a linguagem jurídica não é uma linguagem objetivo-denotativa acrescida de uma função diretiva ou prática; é uma linguagem em si, normativamente e institucionalmente, performativa que, como tal, se subtrai aos esquemas de análise puramente lógico-empírica. Sendo o direito o que é e tendo a sua linguagem esta índole, a interpretação jurídica não é mera determinação analítico-linguística de expressões das leis - a entender, como quaisquer outras expressões significantes, sobretudo pelo seu texto -, mas a compreensão prático-normativa do critério normativo-jurídico que o caso decidendo solicita da norma legal. "Norma não a ler no seu dito comum, mas a reconstituir no seu sentido performativo-constitutivo específica e pragmaticamente jurídico" (NEVES, 1995, p. 266).

Mas se hoje temos esta ideia de que o pensamento lógico-dedutivo não serve para grande parte dos casos que se apresentam ao juiz, isso muito se deve a influência das teorias retóricas, como já foi dito.

Observe-se que a noção aristotélica de dialética, cujas implicações foram sendo ignoradas ao longo da trajetória da filosofia ocidental, não mereceu a atenção dada à demonstração analítica. Dentre os dois modos de raciocinar, prevaleceu esta em detrimento da argumentação dialética, que passou a ser tomado por mera técnica a serviço de interesses mesquinhos - os quais, por não conseguirem se afirmar por sua própria "verdade", se vêm na contingência de lançar mão de quaisquer meios para obter a adesão dos interlocutores. Distinguir o raciocínio dialético do chamado silogismo erístico é fundamental, já que este alicerça-se em premissas apenas prováveis. A dialética parece sair de um esquecimento de vinte e três séculos para, a partir de Chäim Perelman e Theodor Viehweg, entre outros, mostrar que aplicação do direito não é um processo meramente lógico-dedutivo, que este não é capaz de explicar como se opera o interferência dos juízos de valor do aplicador da norma. 
Não sendo um processo meramente lógico-dedutivo e compreendida a possibilidade de ocorrerem decisões diferentes para casos concretos idênticos, o que fere a isonomia, nosso sistema jurídico cada vez mais se preocupa com a utilização abusiva dos princípios e a previsão de um complexo sistema recursal e um rígido sistema de precedentes que vinculem o juiz ao proferir suas decisões, como forma de garantir tratamento semelhante a cidadãos e empresas que procuram o Poder Judiciário.

\section{TENTATIVAS EXTREMADAS PARA SOLUÇÃO DO PROBLEMA GNOSEOLÓGICO DO DIREITO - O CONFRONTO ENTRE DEFENSORES DOS PENSAMENTOS SISTEMÁTICO E PROBLEMÁTICO}

Como vimos, de um lado no deparamos com defensores do entendimento de que, as características específicas do caso concreto ou texto prévio, desde que competentemente interpretadas, poderiam levar do decisor a uma única decisão correta, podendo as demais serem consideradas desvios técnicos ou éticos. No outro extremo, correntes que defendem que a decisão concreta é inteiramente casuística e indutiva, funcionando o texto como justificação a posteriori para uma decisão encontrada (ADEODATO, 2011, p. 10-11). Há quem fale até em fachada de justificação para decisões tomadas com base em interesses, impulsos e gostos.

Os debates entre tais antagonistas tomaram fôlego com a publicação de Tópica e Jurisprudência, de Theodor Viehweg, que em seu bojo rejeita a utilização do pensamento sistemático como metodologia capaz de captar a ciência do direito em sua estrutura. Desde então, não mais cessou a discussão a respeito do assunto, arregimentando defensores em suas frentes de combate.

Ao tratar do assunto, Viehweg faz a distinção entre as duas formas de pensamento, citando Hartmann, para quem "o modo de pensar sistemático procede do todo. A concepção é nele o principal e permanece sempre como dominante. Não há que se buscar um ponto de vista. 0 ponto de vista está adotado desde o princípio. E a partir dele se selecionam os problemas. Os conteúdos do problema que não se conciliam com o ponto de vista são rejeitados. São considerados como uma questão falsamente 
colocada. Decide-se previamente não sobre a solução de problemas, mas sim sobre os limites dentro dos quais a solução pode mover-se"[...] "O modo de pensar aporético procede em tudo ao contrário". Considera ainda que "o modo de pensar aporético não põe em dúvida que o sistema exista e que para sua própria maneira de pensar talvez seja latentemente o determinante. Tem certeza do seu sistema, ainda que não chegue a ter dele uma concepção" (VIEHWEG, 1979, p. 163-164).

Porém Viehweg foi mais além, ao considerar que a estrutura da ciência do direito não poderia ser captada com o auxílio do pensamento sistemático, mas apenas com base na doutrina da Tópica. A posição de Viehweg levou Flume a afirmar que todo pensamento jurídico é pensamento problemático, e cada regulação jurídica é-o de um problema, já que todo o pensamento científico é, em geral, pensamento problemático, visto que problema nada mais é do que uma questão cuja resposta não é de antemão clara (CANARIS, 1989, p. 246).

Observe-se que a crítica de Hartmann não é um ataque frontal ao pensamento sistemático, mas a uma concepção de sistema definitivo e fechado, não modificável, que não existe na ciência do direito. A forma de pensar em ciência é também aporética, e esta não conduz obrigatoriamente à Tópica. Um sistema aberto é suficiente para solucionar a questão abordada por Hartmann (CANARIS, 1989, p. 247).

Segundo Viehweg, os elementos, conceitos e proposições da Ciência do direito, têm que permanecer ligados ao problema e só podem ser entendidos a partir deste. Pretende ainda que estes problemas e proposições só podem, por isso, ser conduzidos a uma implicação à qual o problema se mantenha ligado (CANARIS, 1989, p. 248-249).

Para Canaris, isto é falso ou trivial. É falso quando Viehweg queira ligar os conceitos e proposições da ciência do direito ao problema concreto a propósito do qual eles foram descobertos e desenvolvidos (mais ou menos por acaso): que por exemplo, o contrato com eficácia protetora de terceiros, no início, tenha encontrado aplicação exclusivamente a contratos de locação não diz, só por si, nada contra a utilização desta construção também noutros tipos contratuais. Tudo depende antes de saber se o "novo" problema conflui, materialmente, no essencial, com o até então resolvido. Quando Viehweg, pelo contrário, com o trecho cita- 
do, apenas queira dizer que cada conceito ou cada proposição jurídicos representem um determinado problema jurídico e por isso devam ver-se perante esse pano de fundo, ele merece, sem dúvida, concordância; mas com isso nada mais se diz do que cada resposta se relaciona com uma pergunta e, por consequência, é determinada por esta, essencialmente, no seu significado. É sem dúvida útil colocá-lo sempre diante dos olhos e, por isso, por exemplo, elaborar sempre, muito exatamente, o conteúdo teleológico dos conceitos ou proposições jurídicos; no entanto, não reside aí nada de específico da tópica e, em especial, nenhuma diferenciação perante o pensamento sistemático, mas sim uma evidência que vale, mutatis mutandis, para cada pensamento científico (CANARIS, 1989, p. 249-250).

Salienta ainda que a orientação pelo problema não é pois, de modo patente, o decisivo; para além disso, ela não poderia traduzir em termos teoréticos-científicos nenhum critério de decisão utilizável. Não se nega, naturalmente, com isso que exista, psicologicamente, uma oposição entre pensamento problemático e pensamento sistemático, e que, portanto, o pensamento de um cientista se inflame mais facilmente perante problemas concretos, e se interesse com mais força pelas suas soluções, enquanto o de outro receba os seus estímulos antes por via do sistema e encontra satisfação na construção dele; no entanto, também esta contraposição não pode ser considerada como um ideal típico, pois também o pensador de problemas não deixará totalmente fora de atenção o sistema, sob cujo pano de fundo só, em regra, se pode formular claramente e resolver, por fim, o problema e, inversamente, o pensador do sistema se deve afastar plenamente dos estímulos provenientes do problema, para um enriquecimento e modificação do próprio sistema. Segundo Canaris, a contraposição entre o pensamento problemático e o sistemático não se pode reduzir a uma diferença puramente psicológica, inadequada, em qualquer caso, para dar um qualquer esclarecimento sobre a "estrutura da ciência do direito", tal como se trata na discussão sobre a tópica. Deve-se insistir nisso, expressamente, ou não pudesse o fascínio da tópica tantas vezes exerce, assentar, não por último, no mal-entendido de que só ela garante o verdadeiro pensamento problemático. "Na verdade, os seguidores da tópica assumem, porém, para si, com esta afirmação, um serviço que lhes não compete ou, em qualquer caso, apenas a eles" (CANARIS, 1989, p. 250-251). 
Posteriormente, Viehweg procurou minimizar sua oposição ao pensamento sistemático, dirigindo seus ataques à utilização de um sistema dedutivo na aplicação do direito. Não existiria entre os pensamentos tópico e sistemático nenhuma oposição fundamental, sendo possível a junção de ambos num sistema tópico. Porém, torna-se difícil tal conexão, já que o modo de pensar proposto por Viehweg, com ele não se adequaria. Canaris comenta: "isso é no entanto, uma contradição em si; pois um processo que seja "parco em conexões", que apenas "pretenda dar indicações" e que esteja orientado essencialmente ao problema singular, o mais estreitamente formulado possível, logo ao caso singular nunca prossegue a ideia da unidade e da ordem interior, não servindo, por isso, os postulados básicos do conceito de sistema; assim Viehweg não anda em torno daqueles poucos princípios gerais que constituem a unidade de uma disciplina, mas antes pelo contrário, de multiplicidade de pontos de vista mais ou menos precisos. Quando ele fala agora num "sistema tópico", não só ele nada traz para o esclarecimento da problemática, como pelo contrário, retira ao conceito já fortemente confuso do "topos" os seus últimos contornos" (CANARIS, 1989, p. 243-244).

A Tópica é insuficiente como método de atuação do intérprete-aplicador do direito no processo decisório, já que procura legitimar-se somente na aceitação de argumentos que integram a discussão. Esta apresenta-se como única instância de controle.

0 fato de os defensores do pensamento tópico se insurgirem contra o pensamento lógico-formal no direito deve ser encarado com naturalidade, já que na atualidade há uma espécie de consenso entre aqueles que estudam com seriedade o assunto, de que a utilização do procedimento lógico-dedutivo é insuficiente para a solução de casos concretos.

O próprio Perelman, que numa primeira fase procura demonstrar que julgamentos de valor são inteiramente arbitrários, insuscetíveis de tratamento racional, numa outra fase posterior percebe que considerar irracional a aplicação do direito importaria renunciar a qualquer filosofia prática e abandonar a disciplina da conduta humana ao sabor de emoções e interesses, quer dizer, confiá-la à violência. Nessa fase, elege como projeto de pesquisa uma "lógica dos julgamentos de valor", objeto de estudo da chamada nova retórica. Afasta interpretações jurídicas 
verdadeiras, contentando-se com oportunas (e diria eu, adequadas), no que procura demonstrar o esgotamento do modelo cientificista de conhecimento do direito. 0 direito passa a ser pensamento tecnológico e não científico, tendo como consequências a perda do caráter normativo da teoria do conhecimento jurídico e integração entre a produção doutrinário-acadêmica e o cotidiano do profissional do direito. Abandonam-se procedimentos que deveriam ser seguidos para atingimento da certeza e verdade do conhecimento para preocupar-se com a descrição do processo de produção do conhecimento do direito, não mais postulando a adoção de determinado método como pressuposto de qualificação desse conhecimento (COELHO, 1996, p. XVII).

Aos poucos, porém, os ontológicos foram assumindo que a retórica tem uma função a cumprir dentro da ciência do direito, sempre que faltem valorações jurídico-positivas suficientemente concretizadas, pois neste caso, as possibilidades do pensamento sistemático se deparam com limites de difícil transponibilidade.. Nestes casos, só há possibilidade de preenchimento do conteúdo e alcance das normas, por meio da atuação livre do juiz, que deve decidir acerca da máxima de comportamento correto. São casos em que a decisão depende unicamente de sua valoração, devendo o aplicador considerar os valores e as intuições jurídicas, culturais e sociais dominantes na comunidade jurídica em causa, devendo assim buscar o auxílio da retórica.

Passou-se a admitir que no caso de o sistema não oferecer soluções para o caso concreto, o juiz deve observar os diversos pontos de vista a serem considerados, fornecendo-lhe a retórica argumentos a serem experimentados na solução do problema. Entre os principais argumentos jurídicos utilizados pelo aplicador do direito, a doutrina costuma indicar os seguintes: argumento $a b$ absurdum, que no plano da retórica tem utilização quando a demonstração conseqüente de uma proposição nos conduz a uma conclusão manifestamente inaceitável, o que nos obriga a reconhecer a "verdade" da proposição oposta; argumento ab auctorictatem, que procura provar uma tese qualquer, utilizando-se dos atos ou opiniões de uma pessoa ou de um grupo que a apoiam, fundando-se assim no prestígio da pessoa ou do grupo invocado; argumento a contrario sensu, que consiste em concluir de uma proposição admissível pela 
proposição que lhe é oposta; argumento ad hominem, conhecido também como ex concessis, corresponde a um argumento que limita a validade de uma tese a aquilo que cada qual está disposto a conceder, aos valores que se reconhecem, aos fatos com os quais se está de acordo; argumento ad rem, que concerne às coisas mesmas e à verdade enquanto aceitas supostamente por todos; argumento a fortiori (Non debet, cui plus licet, quod minus est non licere - Não deve ser proibido o menos a quem é lícito o mais ) ; argumento a maiori ad minus, pelo qual passamos da validade de uma disposição mais extensa para validade de outra menos extensa; argumento a minori ad maius, com o qual se passa da validade de uma disposição menos extensa para outra mais extensa; argumento a pari ou a simile, aquele que relaciona dois casos entre si, considerados semelhantes, concluindo que se, para ambos, vale a mesma hipótese, devem valer também as mesmas consequências; argumento a posteriori, que se refere a um raciocínio que remonta das consequências aos princípios, daquilo que é condicionado àquilo que condiciona, repousando sua força no conhecimento das consequências; argumento a priori, consistindo em concluir dos princípios para as consequências, das causas para os efeitos, do condicionante para o condicionado; argumento silogístico ou entinema, que corresponde ao silogismo imperfeito ou retórico, que tem força de argumento de quase-dedução, dando a impressão de um rigor lógico, que na realidade não existe; argumento exemplar ou exempla, baseando-se no princípio da semelhança, tendo os exemplos maior força argumentativa quanto maior for a semelhança entre eles e deles com o caso ao qual se aplicam; entre outros (FERRAZ JÚNIOR, 1988, p. 306-314).

Chegou assim uma parte dos estudiosos da metodologia jurídica à conclusão de que a retórica tem uma função complementadora do pensamento sistemático, baseando-se na equidade, na tendência generalizadora de justiça, orientada para o caso concreto, em cujo processo decisório não se podem rejeitar liminarmente os pontos de vista que se lhe apresentam.

Para eles, os pensamentos sistemático e tópico não são opostos exclusivistas, nem estão isolados um em frente ao outro, mas se complementam e se interpenetram. E quanto maior o conteúdo ideológico dos textos jurídicos, mais deficiente torna-se o pensamento lógico-sistemático, em 
sua postura sintático-semanticamente isolada, ampliando-se o quantum de interferência do modo de pensar tópico, com sua atitude semântico-pragmaticamente contextualizada. Isto significa que o recurso às "técnicas" argumentativas torna-se mais importante na proporção em que se intensifica o caráter ideológico dos textos normativos, restringindo-se, em contraposição, o valor dos modelos axiomáticos. Os textos constitucionais, por exemplo, geralmente são dotados de grande conteúdo ideológico, propiciando oportunidade para o modo de pensar tópico.

\section{A TENTATIVA DE CONCILIAR OS OPOSTOS DANDO MAIOR ÊNFASE AO PENSAMENTO PROBLEMÁTICO}

Revela-se bastante limitada essa perspectiva metodológica de se enxergar no pensamento problemático uma mera "reserva técnica" colocada à disposição do aplicador para utilização naqueles casos em que o ordenamento jurídico não nos fornece num primeiro momento uma decisão para o caso concreto que se apresenta.

Nesse enfoque da questão e em busca de uma compatibilização que dê maior relevância ao pensamento problemático na atividade do realizador do direito, demonstrando, porém, as limitações da tópica e a aproximação da atividade decisória da hermenêutica, Castanheira Neves procura traçar um paralelo entre os pensamentos hermenêutico e tópico, demonstrando a possibilidade de compatibilização entre ambos, afastando o radicalismo daqueles que defendem a busca do consenso dos participantes do discurso como único ponto de referência no achamento da decisão. Salienta o autor que a tópico-retórica tem seu núcleo no problema-controvérsia, a referência problemático-contextual a topoi (ou loci communi) , a heresis (ou inventio) , a estrutura dialógica e o processo dialético-argumentativo, etc; a hermenêutica com o seu todo significante, o referente e a pré-compreensão, o círculo hermenêutico e a concretização ( applicatio), a tábua dos cânones, etc. Bem conhecidas em si e nas suas relações com o pensamento jurídico - a tópico-retórica e argumentativa depois de Viehweg e Perelman, a hermenêutica depois de Betti, Gadamer e Esser. 0 tópico-retórico visa e procura fundamento num a posteriori consensus persuasivo, enquanto o jurídico pressupõe e encontra funda- 
mento numa a priori validade normativamente vinculante - o consensus é resultado contingente numa participação situacional, a validade é pressuposição universal (transindividual) que dá sentido e critério à própria comunicação participativa - Rousseau diria que o consensus é la volonté de tous e a validade la volonté générale. Depois na tópico-retórica os topoi, enquanto tais, são entre si equivalentes, a sua diferença de força persuasiva é função apenas da concludência concreta da argumentação, e no jurídico as objetivações da sua normatividade (nos valores, princípios, normas, etc.) têm uma índole dogmaticamente vinculante e preferem por isso a quaisquer outros topoi invocáveis. Por outro lado, na tópica-retórica "a discussão é a única instância de controle"- para usarmos uma formulação de Viehweg -, mas já no jurídico, e concretamente no jurídico decisório de realização judicativa, a instância de controle é o terceiro imparcial de uma institucional instância autoritária (v.g., o tribunal). Sendo assim, e sobretudo pelas notas tanto de uma pressuposta validade normativa como do caráter dogmático da sua objetivação, a juridicidade parece aproximar-se mais da hermenêutica - o que seria, aliás, só o retomar de uma afinidade secular. Ressalva, porém, que esta afinidade tem limites decisivos, tais como: as exigência regulativas deste pensamento não se cumprem numa "doutrina de um correto compreender" mas de um justo decidir; não na correção cognitiva ou verdade, mas a justeza decisória ou a justiça são valores polares; salienta a intervenção da mediação judicativa com a sua específica dimensão problemática e autonomia constitutiva e que não se trata apenas de conhecer o sentido de uma significação cultural numa concreta situação de compreensão e em referência a esta, mas de ajuizar decisoriamente do mérito normativo de um problema prático concreto na perspectiva de uma fundamentante validade. Assim, por seus caracteres praxístico, constitutivo e normativo a jurídica decisão judicativa não pode ser um ato simplesmente hermenêutico. Considera que a dialética entre sistema e problema numa intenção judicativa de realização normativa seria a racionalidade jurídica a considerar. 0 pensamento jurídico veria atualmente o seu objeto problemático não já na norma (na mera interpretativo-dogmática determinação do direito positivo), mas essencialmente no caso (na decisão judicativa do problema jurídico concreto) (NEVES, 1995, p.274-275). 
Nessa linha, ou seja, a de recusar a possibilidade de reconhecer um sentido normativo em abstrato para a norma, ou seja, reconhecer que é na perspectiva problemática do caso que a norma é interrogada e só nessa sua interrogação para o caso oferecerá a sua normatividade, encontram-se o pensamento jurídico tópico-argumentativo de Viehweg, Perelman, Esser e Wieacker, o pensamento da decisão racional-argumentativa de M. Kriele e o pensamento hermenêutico-prático de Esser.

Caminhamos assim no mesmo sentido de Castanheira Neves, para quem o punctum crucis do atual pensamento metodológico-jurídico de sentido jurisprudencial está justamente no modo de compreender e assumir metodicamente a dialética entre sistema e problema, enquanto coordenadas metodologicamente complementares e irredutíveis do judicium jurídico. 0 que excluirá tanto uma pura tópica como um estrito normativismo. Pois por um lado, se a intenção axiológico-normativa do direito vai logrando a sua objetiva manifestação e a sua universal determinação na normatividade do sistema jurídico - com a pluralidade dos seus elementos normativos, os princípios (os fundamentos), as normas (os critérios) e a elaboração reconstituinte da dogmática (a racionalização e institucionalização normativo-jurídicas), mas integrada numa constituenda e totalizante unidade intencional -, por outro lado, a consideração da dimensão problemática abre continuamente o sistema e só ela permite uma realização adequada e justa (materialmente correta e normativamente plausível) da juridicidade. Assim quando a realização do direito possa operar pela mediação de uma norma - i. é, quando uma norma jurídica positiva possa ser utilizada como imediato critério normativo -, essa norma será apenas o eixo de um processo metodológico complexo em que, por um lado, ela se vê amplamente transcendida (transcendida a sua positiva normatividade abstrata) já pela intenção normativo-jurídica fundamentante manifestada pelo sistema, já pelo problemático concretum decidendo; e em que, por outro lado, vem a ser interpretada pela assimilação, ou enquanto assimila, o resultado normativo-jurídico da dialética metodológica da própria realização concreta do direito que a utiliza (NEVES, 1995, p. 279) ${ }^{3}$. 


\section{CONCLUSÃO}

Não há muito sentido em atribuir aos retóricos a pecha de conservadores do direito. Foram muitos os contributos das teorias retóricas, que têm demonstrado as fragilidades do pensamento ontológico. Pensamentos sistemático e problemático deixam de ser opostos exclusivistas para serem entendidos como partes integrantes do processo de realização do direito. Nesse processo, relativiza-se a ideia de verdade e mostra-se de pouca ou nenhuma utilidade o esquema clássico lógico-dedutivo de interpretação/aplicação do direito, partindo-se da ideia de que a linguagem não é meio para o mundo real, mas o único mundo perceptível, o que nos leva, em muitos casos, à impossibilidade de defender a existência de uma única solução correta para o caso concreto. Tal realidade já foi assimilada pelos sistemas processuais, que enfatizam a busca de soluções isonômicas por meio de um complexo sistema recursal e de um sistema de precedentes obrigatórios que visam dar harmonia a algo que, intrinsecamente, tende a ser desarmônico.

\section{NOTAS}

1 Para Engish, os conceitos indeterminados seriam aqueles de conteúdo e extensão em larga medida incertos. Os conceitos indeterminados, porém, precisam de uma delimitação por parte do intérprete, que deve fixar seu conteúdo e alcance. "Conceitos como escuridão e perigo seriam conceitos naturalísticos indeterminados. Conceitos como crime e ato administrativo, conceitos jurídicos indeterminados". Admite-se a existência de conceitos indeterminados normativos. Para uns seriam aqueles conceitos não perceptíveis pelos sentidos, mas que só em conexão com o mundo das normas se tornam representáveis e compreensíveis. Para Engish, os conceitos jurídicos normativos stricto sensu (por oposição aos conceitos jurídicos descritivos) teriam o seu momento específico na valoração que é necessária para aplicar ao caso concreto um conceito normativo. Careceriam assim de um preenchimento valorativo. Os conceitos discricionários são aqueles que permitem uma autonomia de valoração pessoal do órgão aplicador do direito, na decisão dos casos concretos. O legislador transferiria ao aplicador do direito a função de, utilizando-se de sua percepção e vontade, de acordo com os deveres do cargo, determinar o fim próximo de sua atuação. As cláusulas gerais contrapõem-se à elaboração casuística da hipótese legal. A hipótese legal é formulada com grande generalidade, possibilitando o tratamento jurídico de inúmeros casos e a adaptação das normas a uma realidade social em constante mutação (ENGISH, 1988, p. 209-228). Note-se que os estudiosos da semiótica jurídica entendem ser grande a dificuldade de encontrar-se conceitos absolutamente determinados, de significação unívoca, no campo da ciência do direito. Até pela função simbólica, que é própria da linguagem, onde muitas vezes o emissor quer fazer entender sua mensagem com determinado sentido e o receptor a compreende de maneira diversa.

2 Exemplificando com o direito positivo alemão, Larenz explica que muitos conceitos jurídicos, e precisamente os mais importantes, como por exemplo, "negócio jurídico", “pretensão”, “ilícito”, não estão definidos na lei; outras definições legais, como a de "negligência” no § 276 do BGB, resultam 
incompletas ou equívocas. Com frequência, uma mesma expressão é usada em diferentes leis, e inclusivamente na mesma lei, em diferentes sentidos; assim a expressão "condição de negócio alheio", nos § 662 e 667 do BGB, por um lado, e no § 675, por outro" (LARENZ, 1989, p. 376).

3

Segundo o autor, o sentido hipotético da norma será submetido a uma experimentação problemático-decisória em referência à relevância jurídica material do caso concreto. Segundo Castanheira Neves, os limites entre o direito que é e o direito que deve ser - distinção de que se alimentava o positivismo jurídico - se diluem, pois que é num dever-ser assumido autonomamente pelo pensamento jurídico em termos fundamentantes e constituintes que o direito positivo acaba por ter o critério decisivo da sua própria realização (NEVES, 1995, p. 281).

\section{REFERÊNCIAS}

ADEODATO. João Maurício. Filosofia do direito: uma crítica à verdade na ética e na ciência (através de um exame na Ontologia de Nicolai Hartmann). São Paulo: Saraiva, 1996.

. Ética e retórica: para uma teoria da dogmática jurídica. 3. ed. São Paulo: Saraiva, 2007.

. Uma teoria retórica da norma jurídica e do direito subjetivo. São Paulo: Noeses, 2011.

ALEXY, Robert. Teoria da argumentação jurídica: a teoria do discurso racional como teoria da justificação jurídica. Tradução de Zilda Hutchinson Schild Silva e Claudia Toledo. 2. ed. São Paulo: Landy Editora, 2005.

ALVES, Alaôr Caffé. Dialética e Direito: linguagem, sentido e realidade: fundamentos a uma teoria crítica da interpretação do direito. Barueri: Manole, 2010.

ATIENZA, Manuel. 0 direito como argumentação. Tradução de Manuel Poirier Braz. Lisboa: Escolar Editora, 2014.

ÁVILA, Humberto Bergman. Subsunção e concreção na aplicação do direito. In: MEDEIROS, Antônio Paulo Cachapuz. Faculdade de Direito da PUCRS: o ensino jurídico no limiar do novo milênio. Porto Alegre: Edipucrs, 1997. p 413-465.

CANARIS, Claus-Wilhelm. Pensamento sistemático e conceito de sistema na ciência do direito. Tradução de A. Menezes Cordeiro. Lisboa: Fundação Calouste Gulbenkian, 1989.

CARVALHO, Aurora Tomazini de. Curso de teoria geral do direito: o constructivismo lógico-semântico. 3. ed. (revista e ampliada). São Paulo: Noeses, 2013.

COELHO, Fábio Ulhoa. Prefácio. In: PERELMAN, Chaim; OLBRECHTS-TYTECA, Lucie. Tratado da Argumentação: a nova retórica. São Paulo: Martins Fontes, 1996. 
CORDEIRO. Antônio Manuel da Rocha e Menezes. Introdução. In: CANARIS, Claus-Wilhelm. Pensamento sistemático e conceito de sistema na ciência do direito. Lisboa: Fundação Calouste Gulbenkian, 1989.

ENGISH, Karl. Introdução ao pensamento jurídico. 6. ed. Lisboa: Calouste Gulbenkian, 1988.

FERRAZ JÚNIOR. Tércio Sampaio. Introdução ao estudo do direito: técnica, decisão, dominação. São Paulo: Atlas, 1988.

Direito, retórica e comunicação: subsídios para uma pragmática do discurso jurídico. 3. ed. São Paulo: Atlas, 2015.

LARENZ, Karl. Metodologia da ciência do direito. Tradução de José Lamego. 2. ed. Lisboa: Fundação Calouste Gulbenkian, 1989.

MÜLLER, Friedrich. 0 novo paradigma do direito: introdução à teoria e metódica estruturantes do direito. São Paulo: RT, 2007.

NEVES, Antônio Castanheira. 0 actual problema metodológico da realização do direito. In: NEVES, A. Castanheira. Digesta: escritos acerca do direito, do pensamento jurídico, da sua metodologia e outros. Coimbra: Coimbra Editora, 1995. v. $2^{\circ}$.

SCHMIDT, Lawrence K. Hermenêutica. Tradução de Fábio Ribeiro. 3. ed. Petrópolis: Vozes, 2014.

SOUTO, Cláudio. Natureza, mente e direito: para além do usual acadêmico. 3. ed., revista. Porto Alegre: Sérgio Antônio Fabris Editor, 2015.

TARUFFO, Michele. Uma simples verdade: o juiz e a construção dos fatos. São Paulo: Marcial Pons, 2012.

VESTING, Thomas. Teoria do direito: uma introdução. Tradução de Gercélia B. de O. Mendes. São Paulo, Saraiva, 2015.

VIEHWEG, Theodor. Tópica e jurisprudência. Tradução de Tércio Sampaio Júnior. Brasília: Departamento de Imprensa Nacional, 1979. vol. 1. Coleção Pensamento Jurídico Contemporâneo.

Recebido em: 13-10-2016

Aprovado em: 31-5-2017 


\section{Lúcio Grassi de Gouveia}

Doutor em Direito pela Universidade Clássica de Lisboa. Mestre em Direito pela Universidade Federal de Pernambuco (UFPE). Pesquisador do Grupo de Pesquisa Processo, Tecnologia e Hermenêutica da Universidade Católica de Pernambuco. Professor Adjunto II da Universidade Católica de Pernambuco (Graduação, Mestrado e Doutorado). Secretário Adjunto do Instituto Brasileiro de Direito Processual (IBDP). Conselheiro Fiscal da Associação Brasileira de Direito Processual (ABDPRO). Membro da Associação NorteNordeste dos Professores de Processo (ANNEP). Juiz de Direito em Recife-PE. E-mail: luciograssi13@gmail.com

Universidade Católica de Pernambuco. Programa de Pós-Graduação em Direito.

Rua Almeida Cunha, 245. bloco G4, 8o andar, setor A. Boa Vista, Recife/PE. CEP: 50.050- 480.

\section{Mateus Costa Pereira}

Doutorando e Mestre em Direito Processual pela Unicap. Professor de Processo Civil da Universidade Católica de Pernambuco (Unicap). Pesquisador do Grupo de Pesquisa Processo, Tecnologia e Hermenêutica da Unicap. Membro fundador e Diretor de Comunicação Social da Associação Brasileira de Direito Processual (ABDPro). Membro da Associação Norte Nordeste de Professores de Processo (Annep) e do Conselho Editorial da Revista Brasileira de Direito Processual (RBDPro). Advogado. E-mail: mateuspereira@abdpro.com.br

Universidade Católica de Pernambuco. Programa de Pós-Graduação em Direito.

Rua Almeida Cunha, 245. bloco G4, 8o andar, setor A. Boa Vista, Recife/PE. CEP: 50.050- 480. 
